contribute to identifying axSpA in CBP patients indicating these family elements may not be very useful for diagnosis. A PFH of AS or AAU however may be useful in finding cases in low prevalence settings as these were correlated with HLA-B27 carriership.

Disclosure of Interest: None declared

DOI: 10.1136/annrheumdis-2017-eular.4671

\section{OP0245 EMPLOYMENT PERSPECTIVES OF PATIENTS WITH ANKYLOSING SPONDYLITIS IN THE BIOLOGICS ERA}

C. Webers ${ }^{1,2}$, L. Vanhoof ${ }^{1}$, S. van Genderen ${ }^{1,2}$, G. Plasqui ${ }^{3}$, L. Heuft ${ }^{4}$, M. van ${\text { de } \text { Laar }^{5} \text {, J. Luime }}^{6}$, D. van der Heijde ${ }^{7}$, A. Spoorenberg ${ }^{8}$, A. Boonen ${ }^{1,2}$. ${ }^{1}$ MUMC; ${ }^{2}$ CAPHRI; ${ }^{3}$ Human Biology, UM, Maastricht; ${ }^{4}$ Laurentius, Roermond; ${ }^{5}$ MST, Enschede; ${ }^{6}$ Erasmus MC, Rotterdam; ${ }^{7}$ LUMC, Leiden; ${ }^{8}$ UMCG, Groningen, Netherlands

Background: In the pre-biologics era, employment of patients with ankylosing spondylitis (AS) was decreased when compared to the general population. However, information on standardized employment since the introduction of biologicals is lacking. Also, while mastery (control over disease) has been identified as strong predictor of work outcome within patients with AS, it is not known whether such personality trait plays a similar role in patients compared to population subjects.

Objectives: To update the knowledge on employment and contributing factors, in particular personal factors, among Dutch patients with AS compared to general population subjects.

Methods: Data from patients and population controls participating in the Dutch cross-sectional multicenter survey-based Social Participation in AS Study (SPASS) and $\leq 65$ years were used. Standardized employment ratios (SERs) were calculated using indirect standardization after adjusting for age, gender and education and were stratified by disease duration tertiles. Adjusted absolute employment rate (\%) was calculated as "SER[AS] ${ }^{*}$ employment rate [controls]". Modified Poisson regressions were performed to understand the role of mastery as a personal factor (Pearlin's Mastery scale) in patients opposed to controls, independent of socio-demographics (age, gender, education) and health-related factors (comorbidities, Physical Component Summary (PCS) of the SF-36).

Results: 214 patients and 470 controls (127 [59.3\%] and 323 [68.7\%] males; mean age of 48.3 [SD 10.4] and 39.3 [SD 12.7] years, respectively) completed the online questionnaire in 2011. SERs $(95 \% \mathrm{Cl})$ of patients with AS with controls set as reference $(1.00)$ were $0.83(0.69-0.98)$ for the total group, 0.84 [0.67-1.04] for males and 0.83 [0.59-1.07] for females. There was no significant difference in SER between those with short or long disease duration (Figure 1). Adjusted absolute employment rate (\%) of patients with AS was $14 \%$ lower compared to controls ( $69 \%$ vs. $84 \%$ ). In both patients and controls, higher PCS (SF-36) was associated with being employed. While AS patients with higher (better) mastery were more likely to be employed, such association was not seen in controls $\left(\mathrm{p}<0.01\right.$ for interaction group ${ }^{*}$ mastery) (Table).

Table 1. Multivariate Poisson regression exploring determinants of work participation, stratified by group (AS vs. controls)

\begin{tabular}{lccccccc}
\hline Variable & \multicolumn{3}{c}{$\mathrm{AS}(\mathrm{n}=213)$} & & \multicolumn{3}{c}{ Controls $(\mathrm{n}=465)$} \\
\cline { 2 - 4 } \cline { 7 - 8 } & IRR & $95 \% \mathrm{Cl}$ & $\mathrm{p}$ & & IRR & $95 \% \mathrm{Cl}$ & $\mathrm{p}$ \\
\hline Age, years & 0.99 & $0.98-1.00$ & $<0.01$ & & 1.00 & $0.99-1.00$ & 0.07 \\
Gender, male & 1.13 & $0.91-1.39$ & 0.26 & & 1.08 & $0.99-1.19$ & 0.09 \\
Education, high & - & & $\mathrm{ns}^{\dagger}$ & & 1.09 & $1.01-1.18$ & 0.02 \\
Comorbidity (SCQ, 0-39) & 0.97 & $0.94-1.01$ & 0.12 & & 0.97 & $0.94-1.01$ & 0.14 \\
SF-36 PCS (0-100) & 1.02 & $1.00-1.03$ & $<0.01$ & & 1.01 & $1.00-1.02$ & 0.02 \\
Mastery (7-28) & 1.03 & $1.00-1.05$ & 0.03 & & - & & $\mathrm{ns}^{\dagger}$
\end{tabular}

†Value not significant and no confounder.

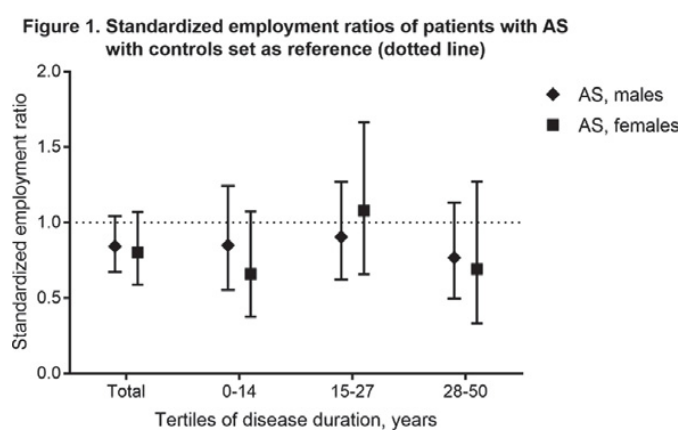

Conclusions: In the biologics era, employment among Dutch patients with AS remains reduced when compared to the general population, also in those with less than 15 years disease duration. As mastery in patients is independently associated with work outcome, it is worthwhile exploring whether improving personal self-management skills supports future worker participation.

Disclosure of Interest: None declared

DOI: 10.1136/annrheumdis-2017-eular.3472
FRIDAY, 16 JUNE 2017

RA - causes and courses

\section{OP0246 IMPACT OF DISEASE ACTIVITY MEASURES ON SICK LEAVE IN BIOLOGICS-TREATED PATIENTS WITH RHEUMATOID ARTHRITIS: OBSERVATIONAL DATA FROM SOUTHERN SWEDEN}

J.K. Wallman $^{1}$, J.K. Söderling ${ }^{2}$, A. Gülfe ${ }^{1}$, L.-E. Kristensen ${ }^{3}$, M. Neovius ${ }^{2}$, T. Olofsson ${ }^{1}$. 'Lund University, Department of Clinical Sciences Lund, Rheumatology, Lund; ${ }^{2}$ Karolinska Institutet, Department of Medicine, Clinical Epidemiology Unit, Stockholm, Sweden; ${ }^{3}$ The Parker Institute, Department of Rheumatology, Copenhagen University Hospital, Frederiksberg and Bispebjerg, Denmark

Background: Sick leave generally represents the earliest phase of work-loss in rheumatoid arthritis (RA) patients, often on the trajectory towards more permanent disability pension. Sick leave may still change with disease activity fluctuations and is thus potentially reversible and accessible for interventions. However, data remain scarce on the importance of modifiable, non-composite disease activity measures for subsequent sick leave in RA patients treated with biologics.

Objectives: To study the impact of common, non-composite disease activity measures on sick leave in biologics-treated RA patients.

Methods: Study visits of biologics-treated RA patients of working-age $(<65 \mathrm{y})$ without disability pension, monitored in the population-based, observational South Swedish Arthritis Treatment Group register 2005-2011, were included (5151 visits; 957 patients). We performed association analyses between various non-composite disease activity measures at each visit and number of objectively assessed sick leave days during the month thereafter, retrieved from the Social Insurance Agency. Separate generalised estimating equation regression models were used, adjusting for age, sex, educational level, disease duration, number of previous biologics, time from start of the present biologic, and calendar year of study visit. Analyses were furthermore stratified on sick leave status the month preceding each visit (no sick leave $=0$ days out of 30 ; partial sick leave $=1-29$ days and full sick leave $=30$ days) and results are presented as standardised beta coefficients for comparability, with bootstrap-generated $95 \%$ confidence intervals. The composite 28-joint disease activity score (DAS28) and the health assessment questionnaire (HAQ) disability score were included as contrast.

Results: Out of common, non-composite disease activity measures, visual analogue scale (VAS) global and VAS pain were most strongly associated with sick leave days the month after the study visit, irrespective of baseline sick leave status (Figure). Generally, the more objective measures (erythrocyte sedimentation rate, C-reactive protein and swollen joint count (SJC)) had less impact on subsequent sick leave than the more subjective variables (VAS global, VAS pain, evaluator's global and tender joint count (TJC)). As expected, HAQ showed the strongest association.

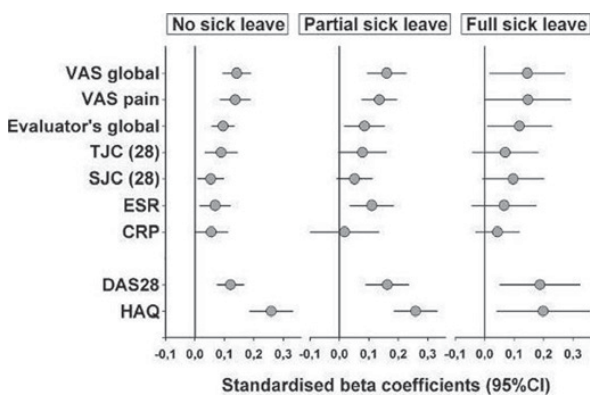

Conclusions: More subjective disease activity measures have greater impact on sick leave in biologics-treated RA patients than do more objective variables, suggesting a stronger focus on the former ones when targeting work-loss or intervening to reduce it.

Disclosure of Interest: J. Wallman Consultant for: Novartis, Celgene and UCB, J. Söderling Grant/research support from: Participated in previous research projects fully or partly funded by Novo Nordisk and Combine Sweden, Consultant for: Served as an external consultant to AbbVie, Merck and Novartis, A. Gülfe: None declared, L.-E. Kristensen Grant/research support from: Oak Foundation, Consultant for: AbbVie, Celgene, BMS, MSD, Novartis, Pfizer, UCB, M. Neovius Grant/research support from: Participated in research projects fully or partly funded by Schering-Plough, AstraZeneca, Novo Nordisk, Pfizer and Roche (unrelated to the current work), Consultant for: Participated in advisory boards for Pfizer (rheumatology) and Abbott (non-rheumatology), T. Olofsson: None declared

DOI: 10.1136/annrheumdis-2017-eular.2883 